\title{
Determining cancer survivors' preferences to inform new models of follow-up care
}

\author{
Peter Murchie ${ }^{\star}, 1$, Patricia F Norwood ${ }^{2}$, Marta Pietrucin-Materek ${ }^{1}$, Terry Porteous ${ }^{3}$, Philip C Hannaford ${ }^{1}$ \\ and Mandy Ryan ${ }^{2}$ \\ ${ }^{1}$ Centre for Academic Primary Care, Division of Applied Health Sciences, University of Aberdeen, Foresterhill, Aberdeen AB25 \\ 2ZD, UK; ${ }^{2}$ Health Economics Research Unit (HERU), Division of Applied Health Sciences, University of Aberdeen, Foresterhill, \\ Aberdeen AB25 2ZD, UK and ${ }^{3}$ Health Services Research Unit (HSRU), Division of Applied Health Sciences, University of Aberdeen, \\ Foresterhill, Aberdeen AB25 2ZD, UK
}

Background: Specialist-led cancer follow-up is becoming increasingly expensive and is failing to meet many survivors' needs. Alternative models informed by survivors' preferences are urgently needed. It is unknown if follow-up preferences differ by cancer type. We conducted the first study to assess British cancer survivors' follow-up preferences, and the first anywhere to compare the preferences of survivors from different cancers.

\begin{abstract}
Methods: A discrete choice experiment questionnaire was mailed to 1201 adults in Northeast Scotland surviving melanoma, breast, prostate or colorectal cancer. Preferences and trade-offs for attributes of cancer follow-up were explored, overall and by cancer site.

Results: 668 (56.6\%) recipients (132 melanoma, 213 breast, 158 prostate, 165 colorectal) responded. Cancer survivors had a strong preference to see a consultant during a face-to-face appointment when receiving cancer follow-up. However, cancer survivors appeared willing to accept follow-up from specialist nurses, registrars or GPs provided that they are compensated by increased continuity of care, dietary advice and one-to-one counselling. Longer appointments were also valued. Telephone and web-based follow-up and group counselling, were not considered desirable. Survivors of colorectal cancer and melanoma would see any alternative provider for greater continuity, whereas breast cancer survivors wished to see a registrar or specialist nurse, and prostate cancer survivors, a general practitioner.
\end{abstract}

Conclusions: Cancer survivors may accept non-consultant follow-up if compensated with changes elsewhere. Care continuity was sufficient compensation for most cancers. Given practicalities, costs and the potential to develop continuous care, specialist nurseled cancer follow-up may be attractive.

After completing their primary treatment, most patients with cancer enter structured cancer follow-up aimed at detecting cancer recurrence or metastasis and monitoring the short-and long-term toxicities of treatment (Hellbom et al, 2011). Follow-up guidance in many countries tends to focus on secondary care specialist provision during scheduled hospital appointments (Dorsey, 2010; Frew et al, 2010; Cancer Australia, 2015; National Cancer Institute, 2015; National Institute for Health and Care Excellence, 2015; Scottish Intercollegiate Guideline Network, 2015). In the UK cancer follow-up is largely delivered by consultants and senior secondary care doctors who are fully trained in cancer specialties. Consultants are supported by registrars and mid-career secondary care doctors training to become consultants. Secondary carefocused provision is reflected in previously reported preferences of cancer survivors for follow-up care (Kimman et al, 2010; Bessen et al, 2014). However, as the number of people surviving cancer grows, the cost of such follow-up increases (Davies and Batehup, 2011). There is also growing evidence that current models of

*Correspondence: Dr P Murchie; E-mail: p.murchie@abdn.ac.uk

Received 10 June 2016; revised 27 September 2016; accepted 4 October 2016; published online 1 November 2016

(c) 2016 Cancer Research UK. All rights reserved 0007-0920/16 
follow-up care can be suboptimal, with many cancer survivors having unmet practical, physical and psychological needs (Aaronson et al, 2014). These key drivers have led to the pursuit of cancer follow-up that is cheaper and more effective. Alternative models varying the healthcare professional, location and mode of delivery of follow-up have been developed, and in some places implemented, providing promising results (Grunfeld et al, 1999, 2011; Murchie et al, 2010; McFarlane et al, 2012).

As follow-up care evolves, it is important to recognise the importance of patient preferences, and to consider the acceptability of new and potential models of follow-up to the growing population of cancer survivors (Brennan and Strombom, 1998; Dirksen et al, 2013). Discrete choice experiments (DCEs) offer one method of doing so and have been used to explore patient preferences in the delivery of healthcare (Ryan et al, 2008). DCEs provide information about what components (attributes) of a service respondents would prefer to receive, as well as the tradeoffs they appear willing to make between attributes. Respondents to a DCE questionnaire are presented with a number of 'choice questions', in which they are asked to indicate their preferred choice between two or more alternatives, where at least one attribute is varied systematically between options (Gerard et al, 2008). Previous research has assessed patients' preferences for breast cancer follow-up in The Netherlands and Australia (Kimman et al, 2010; Bessen et al, 2014; Wong et al, 2014). We present here the first study in the UK to explore cancer survivors'

Table 1. Attributes and their associated levels included in the final DCE questionnaire

\begin{tabular}{|c|c|c|c|}
\hline Attributes & Attribute levels & $\begin{array}{l}\text { Variable in } \\
\text { Equation (1) }\end{array}$ & Regression coding \\
\hline \multicolumn{4}{|c|}{ Health care provider } \\
\hline & $\begin{array}{l}\text { Consultant } \\
\text { Registrar/trainee doctor } \\
\text { GP } \\
\text { Specialist nurse }\end{array}$ & $\begin{array}{l}\text { Consult } \\
\text { Regtrainee } \\
\text { GP } \\
\text { SPnurse }\end{array}$ & $\begin{array}{l}\beta 1 \\
\beta 2 \\
\beta 3 \\
\beta 4\end{array}$ \\
\hline \multicolumn{4}{|c|}{ Continuity of care ${ }^{a}$} \\
\hline \multicolumn{4}{|c|}{ Contact mode ${ }^{b}$ and place ${ }^{c}$} \\
\hline & $\begin{array}{l}\text { Face-to-face at hospital } \\
\text { Face-to-face at general practice } \\
\text { Telephone; } \\
\text { Videoconferencing/ web cam/ Skype }\end{array}$ & $\begin{array}{l}\text { FtfHosp } \\
\text { FtfGp } \\
\text { Telephone } \\
\text { Video }\end{array}$ & $\begin{array}{l}\beta 7 \\
\beta 8 \\
\beta 9 \\
\beta 10\end{array}$ \\
\hline \multicolumn{4}{|c|}{ Duration of appointments ${ }^{d}$} \\
\hline \multicolumn{4}{|c|}{ Frequency of appointments ${ }^{e}$} \\
\hline & $\begin{array}{l}3 \text { monthly } \\
6 \text { monthly } \\
9 \text { monthly } \\
12 \text { monthly }\end{array}$ & FreqApp & $\beta 12$ \\
\hline \multicolumn{4}{|c|}{ Length of follow-up ${ }^{f}$} \\
\hline & $\begin{array}{l}1 \text { year } \\
2 \text { years } \\
5 \text { years } \\
10 \text { years }\end{array}$ & LengthFU & $\beta 13$ \\
\hline \multicolumn{4}{|c|}{ Counselling $^{g}$} \\
\hline & $\begin{array}{l}\text { No counselling } \\
\text { Individual counselling } \\
\text { Group counselling } \\
\text { Family counselling }\end{array}$ & $\begin{array}{l}\text { NoCouns } \\
\text { CounsIndiv } \\
\text { CounsGroup } \\
\text { CounsFamily }\end{array}$ & $\begin{array}{l}\beta 14 \\
\beta 15 \\
\beta 16 \\
\beta 17\end{array}$ \\
\hline \multicolumn{4}{|c|}{ 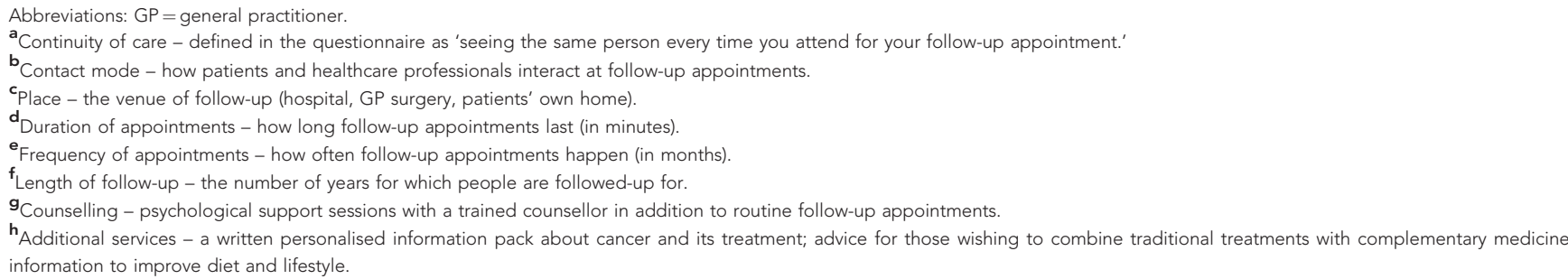 } \\
\hline
\end{tabular}


preferences for follow-up care, and the first to our knowledge to compare the follow-up preferences between survivors of different cancers (breast, prostate, colorectal or melanoma).

\section{MATERIALS AND METHODS}

Designing the DCE. Attributes and associated levels for the DCE were identified in a two-stage process. First, a comprehensive narrative literature review identified characteristics of cancer follow-up that had been reported as important to survivors. A topic schedule was then developed and used in semi-structured qualitative interviews with 27 people currently receiving structured follow-up for melanoma, breast, colorectal or prostate cancer. Interviewees discussed their current follow-up arrangements and alternative ways in which follow-up care might be delivered in the future. The literature review identified two previous DCEs of follow-up preferences in women with breast cancer, one from The Netherlands and one from Australia (Kimman et al, 2010; Bessen et al, 2014). Both suggested that consultant-led follow-up was the preferred model of care.

Our interviews confirmed that this was also the view held by many of our 27 interviewees, with most currently being seen faceto-face by cancer specialists at an outpatient hospital clinic. Cancer follow-up was regarded as important, and most participants were satisfied with the way in which it had been delivered to them so far. Some participants, however, identified a number of aspects of cancer follow-up care, which needed improvement, such as: lack of continuity of care, insufficient appointment time, lack of additional support and the attitude of some physicians. Participants wished to continue to be seen for future follow-up by cancer specialists but stated that they were willing to consider trade-offs between different components of follow-up care. The preferred content of follow-up appointments varied between interviewees. Some participants said that they would like to have additional laboratory tests or extra imaging procedures done as a part of their preferred follow-up. Support for spouse and family members was seen to be an important element of cancer follow-up by some. Interviewees generally perceived continuity of care to be an important aspect of cancer follow-up to build the patient-physician relationship, trust and develop a rapport. In addition, detailed discussions were held with cancer specialists currently providing follow-up care in Northeast Scotland, focusing on different potential models of care and current policy considerations.

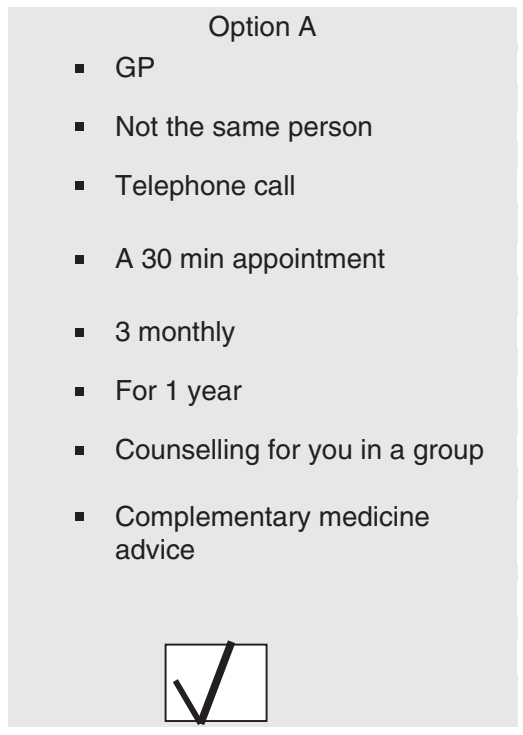

Analysis of the information from the interviews and literature yielded eight attributes, with associated levels, of structured cancer follow-up (see Table 1). A full factorial design consisting of eight (four-level) attributes and one attribute with two levels would have yielded 131072 possible hypothetical scenarios $\left(4^{8} \times 2^{1}=131072\right)$. To reduce the number of hypothetical scenarios, a fractional factorial design was applied using an online catalogue with orthogonal arrays, which resulted in 32 choice sets (http:// neilsloane.com/oadir/ Sloane, 2013). In order to reduce cognitive burden on respondents and maximise response rates, these 32 choices sets were divided into two equal blocks (Watson et al, 2016). Thus, two versions ( $\mathrm{v} 1$ and $\mathrm{v} 2$ ) of the questionnaire were produced, each consisting of 16 DCE paired choice sets and two additional (check-recheck) choice sets to test for response consistency.

A two-stage piloting process followed for both versions of the questionnaire. Draft questionnaires were sent to 56 (28 version 1 and 28 version 2) eligible cancer survivors, with 41 responses received and interviews held with eight respondents to assess ease of completion and obtain suggestions for improvement. Following this, revised questionnaires were sent to another 56 (28 version 1 and 28 version 2) cancer survivors, with 39 responses and further refinement. An example choice set from a final questionnaire is shown in Figure 1.

Recruitment and administering the DCE questionnaire. Full ethical approval to conduct the DCE survey was obtained from the North of Scotland Research Ethics Committee on 17 May 2012. In Grampian, Northeast Scotland, all patients diagnosed with one of the cancers of interest (melanoma, breast, prostate and colorectal cancer) are offered the opportunity to be enrolled in scheduled cancer follow-up according to specific guidelines. Ethics approvals were such that recruitment of patients to complete the DCE had to be conducted by the consultants responsible for their cancer follow-up; no direct contact between researchers and potential questionnaire recipients was permitted without patient permission. The central outpatient administration system was used to produce a list of all attendees to relevant follow-up clinics in the preceding 6 months. Consultants then screened this list and removed the names of patients judged to be unsuitable for the DCE (mainly those with end-stage cancer or cognitive impairment). Potential respondents were contacted by the consultants with details of those agreeing to take part, being notified to the researchers who then randomised individuals to receive one of the two versions of
- Specialist Nurse
The same person
- Video call
- A 5 min appointment
- 6 monthly
- For 2 years
- Counselling for family members
- Diet and lifestyle advice

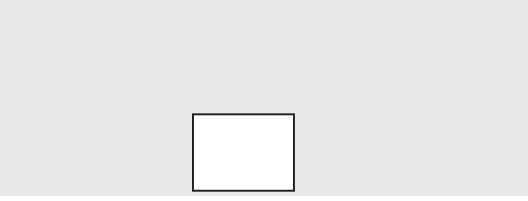

Figure 1. Example of a choice set as presented in final DCE. 
questionnaire. Questionnaires were dispatched in January and February 2013, reminders to non-respondents were sent 3 weeks after the initial mailing, and responses were collected until 30 April 2013.

Data handling. Respondents who provided different answers to two additional and identical check-recheck choice sets distributed among the other choice sets of the questionnaire were deemed to have failed the consistency check and were removed from further analysis $(n=35)$. A $10 \%$ data entry check was made of the remainder (error rate $=0.11 \%$ ).

Data analysis. Analysis of the data was based on random utility theory. Briefly, utility is an economic concept that captures the overall satisfaction or benefit that a consumer obtains from consuming a particular good or service. Random utility theory states that while an individual knows the nature of the utility gained through the choices they make, it cannot be directly observed by researchers (McFadden, 1986). Utility is thus modelled using systematic (explainable) and random (unexplainable) components. The systematic components are used to quantify the importance of attributes and trade-offs. The random component is assumed to follow a logistic distribution. Thus, a binary random-effects logit model was used to analyse the data. Following standard practice, the systematic utility (V) of alternative follow-up service (j) was a linear and additive function of the cancer follow-up attributes and levels, with the categorical variable effects coded:

$$
\begin{aligned}
V_{\mathrm{j}}= & \alpha \beta_{1} \text { Consult }+\beta_{2} \text { RegTrainee }+\beta_{3} \mathrm{GP}+\beta_{4} \text { SPnurse } \\
& +\beta_{5} \text { ContNo }+\beta_{6} \text { ContYes }+\beta_{7} \text { FtfHosp }+\beta_{8} \text { FTfGP } \\
& +\beta_{9} \text { Telephone }+\beta_{10} \text { Video }+\beta_{11} \text { DurApp }+\beta_{12} \text { FreqApp } \\
& +\beta_{13} \text { LengthFU }+\beta_{14} \text { NoCouns }+\beta_{15} \text { CounsIndiv } \\
& +\beta_{16} \text { CounsGroup }+\beta_{17} \text { CounsFamily }+\beta_{18} \text { NoAddservs } \\
& +\beta_{19} \text { Info }+\beta_{20} \text { Cams }+\beta_{21} \text { Diet }
\end{aligned}
$$

Table 1 defines all variable labels. $\alpha$ indicates a general preference to choose option A over option B, everything else being equal. Given the use of generic choices (as opposed to labelled), a negative (positive) coefficient would indicate that the respondents are more likely to choose Option A (B) over Option B (A), everything else being equal. This controls for a potential bias that respondents focus on the first option that is, a left hand side (LHS) bias. The sign on the coefficients $\left(\beta_{1}\right.$ to $\left.\beta_{21}\right)$ indicates whether a change in attribute level has a positive or negative effect on utility of cancer follow-up. The unit of measurement must be considered when interpreting the regression results, for example, $\beta_{11}$ represents the effect on follow-up choice of a 1-minute increase in duration of appointment whereas $\beta_{12}$ represents the effect of a 1month increase in the frequency of appointments. The coefficients for categorical variables should be interpreted as the effect of the presence of the attribute level on the utility of the follow-up care, for example, $\beta_{1}$ shows the utility of seeing a consultant and $\beta_{3}$ the utility of seeing a GP.

Following estimation of equation (1), utility $(V)$ and probability of take-up $(P)$ was calculated for cancer follow-up services with specific attribute levels. Probability of take-up for the current follow-up service, compared with different alternatives, was estimated using the logit Equation (2):

$$
P\left(V_{i}\right)=\frac{\exp \left(V_{i}\right)}{\sum_{j=1}^{J} \exp \left(V_{j}\right)}
$$

Current follow-up service was defined as: consultant-led, no continuity of care, face-to-face at the hospital, no counselling or additional services, $15 \mathrm{~min}$ duration and 5 year follow-up with biannual appointments. Utility and probability values were first estimated overall (i.e., for all cancers combined) and then for each cancer separately.

\section{RESULTS}

Of 1201 questionnaires mailed, 11 were returned undelivered and 10 intended recipients had died. Of the 777 questionnaires returned, 74 were only partially completed and 35 failed both consistency checks; all 109 were excluded from the analysis. Thus, the usable response rate was (668/1180; 56.6\%: 330 for version 1

\begin{tabular}{|c|c|}
\hline & $n(\%)$ \\
\hline \multicolumn{2}{|l|}{ Gender $(n=668)$} \\
\hline $\begin{array}{l}\text { Male } \\
\text { Female }\end{array}$ & $\begin{array}{l}302(45.2) \\
366(54.8)\end{array}$ \\
\hline \multicolumn{2}{|l|}{ Cancer site $(n=668)$} \\
\hline $\begin{array}{l}\text { Breast } \\
\text { Colorectal } \\
\text { Prostate } \\
\text { Melanoma }\end{array}$ & $\begin{array}{l}213(31.9) \\
165(24.7) \\
158(23.6) \\
132(19.8)\end{array}$ \\
\hline \multicolumn{2}{|l|}{ Age (years) $(n=667)$} \\
\hline $\begin{array}{l}\text { Under } 40 \\
41-50 \\
51-60 \\
61-70 \\
71-80 \\
\text { Over } 81\end{array}$ & $\begin{array}{c}20(3.0) \\
76(11.4) \\
147(22.0) \\
219(32.8) \\
175(26.3) \\
30(4.5)\end{array}$ \\
\hline \multicolumn{2}{|c|}{ Time since diagnosis (years) $(n=667)$} \\
\hline $\begin{array}{l}<1 \text { year } \\
1-2 \text { years } \\
2-5 \text { years } \\
\text { Over } 5 \text { years }\end{array}$ & $\begin{array}{c}7(1.1) \\
112(16.8) \\
367(55.0) \\
181(27.1)\end{array}$ \\
\hline \multicolumn{2}{|l|}{ Recurrence $(n=658)$} \\
\hline $\begin{array}{l}\text { Yes } \\
\text { No }\end{array}$ & $\begin{array}{r}80(12.2) \\
578(87.8)\end{array}$ \\
\hline \multicolumn{2}{|c|}{ Currently attending cancer follow-up clinic $(n=663)$} \\
\hline $\begin{array}{l}\text { Yes } \\
\text { No }\end{array}$ & $\begin{array}{l}529(79.8) \\
134(20.2)\end{array}$ \\
\hline \multicolumn{2}{|c|}{ Healthcare provider seen for follow-up ${ }^{a}$} \\
\hline $\begin{array}{l}\text { Consultant } \\
\text { Registrar/Trainee doctor } \\
\text { Specialist nurse } \\
\text { Specialist GP } \\
\text { Own GP } \\
\text { Other } \\
\text { Cannot say }\end{array}$ & $\begin{aligned} 604 & (58.3) \\
140 & (13.5) \\
175 & (16.9) \\
21 & (2.0) \\
69 & (6.7) \\
22 & (2.1) \\
5 & (0.5)\end{aligned}$ \\
\hline \multicolumn{2}{|c|}{ Travelling time to attend follow-up $(n=553)$} \\
\hline $\begin{array}{l}\text { Up to } 15 \mathrm{~min} \\
\text { Between } 15-30 \mathrm{~min} \\
\text { Between } 31-60 \\
61 \text { min or more } \\
\text { Cannot say }\end{array}$ & $\begin{aligned} 83 & (15.0) \\
178 & (32.2) \\
196 & (35.4) \\
95 & (17.2) \\
1 & (0.2)\end{aligned}$ \\
\hline \multicolumn{2}{|c|}{ Cohabitation status, currently living with $(n=665)$} \\
\hline $\begin{array}{l}\text { Spouse/partner } \\
\text { Family } \\
\text { Alone }\end{array}$ & $\begin{array}{l}454(68.3) \\
100(15.0) \\
111(16.7)\end{array}$ \\
\hline
\end{tabular}
and 338 for version 2).

Respondents' characteristics are shown in Table 2. Just over half (54.8\%) of the respondents were female; $31.9 \%$ had breast cancer, $24.7 \%$ colorectal cancer, $23.6 \%$ prostate cancer and $19.8 \%$ melanoma. Most were older than 50 years and 58.3\% were

Table 2. Characteristics of respondents to the DCE 
currently receiving follow-up from a consultant alone, or from a consultant and another healthcare professional. A specialist nurse was involved in the care of $16.9 \%$ of respondents, whereas only $8.7 \%$ reported they received follow-up, fully or partly, from a general practitioner. Of those providing a travelling time to attend follow-up, $67.6 \%$ reported taking between 15 and $60 \mathrm{~min}$. Most respondents lived with a spouse or partner (68.3\%).

Table 3 shows the regression results for all respondents. There was a strong preference for being seen by a consultant $(\beta=0.564 ; P<0.001)$. Being seen by another healthcare professional reduced utility, (i.e., the overall satisfaction that respondents perceived they would obtain from follow-up, indicated by negative coefficients), with GPs being the least preferred option $(\beta=-0.217 ; P<0.001)$. Continuity of care was important, as indicated by the positive coefficient $(\beta=0.379 ; P<0.001)$. There was a preference for being seen face-to-face either at a hospital $(\beta=0.272 ; P<0.001)$ or GP practice $(\beta=0.225 ; P<0.001)$; preference not to have follow-up by telephone or video ( $\beta=-0.122 ; P<0.001$ and $\beta=-0.374 ; P<0.001$, respectively), preference for longer appointments $(\beta=0.007 ; P<0.001)$ and

Table 3. Results of regression analysis (random effects logit) for all respondents

\begin{tabular}{|c|c|c|}
\hline & $\beta$ Coefficient & $P$-value \\
\hline Constant & -0.527 & 0.000 \\
\hline $\begin{array}{l}\text { Healthcare professional } \\
\text { Consultant } \\
\text { Registrar/trainee } \\
\text { GP } \\
\text { Specialist nurse }\end{array}$ & $\begin{array}{l} \\
\quad 0.564 \\
-0.18 \\
-0.217 \\
-0.167\end{array}$ & $\begin{array}{l}0.000 \\
0.000 \\
0.000 \\
0.000\end{array}$ \\
\hline $\begin{array}{l}\text { Continuity of Care }{ }^{a} \\
\text { No } \\
\text { Yes }\end{array}$ & $\begin{array}{r}-0.379 \\
0.379\end{array}$ & $\begin{array}{l}0.000 \\
0.000\end{array}$ \\
\hline $\begin{array}{l}\text { Contact mode }{ }^{\mathbf{b}} \text { and place } \\
\text { Face-to-face hospital } \\
\text { Face-to-face at GP } \\
\text { Telephone } \\
\text { Video }\end{array}$ & $\begin{array}{r}0.272 \\
0.225 \\
-0.122 \\
-0.374\end{array}$ & $\begin{array}{l}0.000 \\
0.000 \\
0.000 \\
0.000\end{array}$ \\
\hline Appointment duration ${ }^{d}$ & 0.007 & 0.000 \\
\hline Frequency of follow-up ${ }^{\mathbf{e}}$ & 0.001 & 0.844 \\
\hline Length of follow-up ${ }^{f}$ & 0.09 & 0.000 \\
\hline $\begin{array}{l}\text { Counselling } \\
\text { None } \\
\text { 1-to-1 } \\
\text { Group } \\
\text { Family }\end{array}$ & $\begin{array}{r}-0.068 \\
0.274 \\
-0.226 \\
0.019\end{array}$ & $\begin{array}{l}0.006 \\
0.000 \\
0.000 \\
0.442\end{array}$ \\
\hline $\begin{array}{l}\text { Additional services }^{\mathbf{h}} \\
\text { None } \\
\text { Information pack } \\
\text { CAMS } \\
\text { Dietary advice } \\
\text { Number of observations } \\
\text { Wald } \chi^{2}(16) \\
\text { Prob }>\chi^{2} \\
\text { Log likelihood }\end{array}$ & $\begin{array}{c}-0.113 \\
0.027 \\
-0.046 \\
0.132 \\
21376 \\
1926.17 \\
0 \\
-13723.992\end{array}$ & $\begin{array}{l}0.000 \\
0.283 \\
0.066 \\
0.000\end{array}$ \\
\hline
\end{tabular}

Abbreviations: CAMS = advice on complimentary medicine; GP = general practitioner. ${ }^{\mathrm{a}}$ Continuity of care - defined in the questionnaire as 'seeing the same person every time you attend for your follow-up appointment.'

${ }^{b}$ Contact mode - how patients and healthcare professionals interact at follow-up appointments.

'Place - the venue of follow-up (hospital, GP surgery, patients' own home).

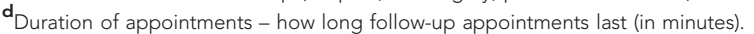

e Frequency of appointments - how often follow-up appointments happen (in months). f Length of follow-up - the number of years for which people are followed-up for.

${ }^{\mathbf{g}}$ Counselling - psychological support sessions with a trained counsellor in addition to routine follow-up appointments.

${ }^{h}$ Additional services - a written personalised information pack about cancer and its treatment; advice for those wishing to combine traditional treatments with complementary medicine; information to improve diet and lifestyle. longer periods of follow-up $(\beta=0.090 ; P<0.001)$. Frequency of follow-up was not a significant attribute. One-to-one counselling was valued $(\beta=0.274 ; P<0.001)$, as was dietary advice $(\beta=0.132$; $P<0.001)$; other additional services were not valued.

Table 4 shows the DCE results by cancer type. Differences in the pattern of results were observed. Compared with other cancer survivors: breast cancer survivors were most averse to GP-led follow-up $(\beta=-0.451 ; P<0.001)$; breast cancer and melanoma survivors were more averse to telephone follow-up $(\beta=-0.115$; $P<0.001$ and $\beta=-0.457 ; P<0.001$, respectively); and, melanoma patients did not value dietary advice $(\beta=0.102 ; \mathrm{p}=0.065)$.

Drawing on Equation (1), and using the parameters estimated in Table 3, the aggregate utility (for all cancers combined) for the current (standard) follow-up service was:

$$
\begin{aligned}
V_{\text {standard }}= & -0.527_{\text {Constant }}+0.564_{\text {Consult }}-0.379_{\text {ContNo }}+0.272_{\text {FtFhosp }} \\
& +0.00715_{\text {DurApp }}+0.095_{\text {LengthFU }}-0.068_{\text {NoCouns }} \\
& -0.113_{\text {NoAddServ }}=0.30
\end{aligned}
$$

Utility levels for some alternative cancer follow-up services are shown in Figure 2. The effect on utility of changing the healthcare provider can be modelled by substituting the coefficient value for an alternative healthcare provider for that of a consultant. The results show that respondents would receive less overall utility from their follow-up care if it is not delivered by a consultant. $\left(V_{\text {standard }}=0.30 ; V_{\mathrm{Reg}}=\right.$ $-0.44 ; V_{\mathrm{GP}}=-0.48$ and $\left.V_{\text {SpecNurse }}=-0.43\right)$. However, if continuity of care was provided, comparable levels of utility $\left(V_{\mathrm{Reg}+\text { cont }}=0.32\right.$; $V_{\mathrm{GP}+\text { cont }}=0.28$ and $V_{\mathrm{SpecNurse}+\text { cont }}=0.33$ ) would be attained, compared with consultant-led follow-up with no continuity of care. If, in addition to continuity, follow-up care also included one-toone counselling and dietary advice, utility would be even higher $\left(V_{\mathrm{Reg}+\text { all }}=0.91 ; \quad V_{\mathrm{GP}+\text { all }}=0.87 \quad\right.$ and $\left.\quad V_{\text {SpecNurse }+ \text { all }}=0.92\right)$. This demonstrates how respondents could be compensated for a model of follow-up care that was not being delivered by a consultant. For example, a follow-up model comprising continuous specialist nurseled care with elements such as counselling or dietary advice would (in theory) produce more utility/satisfaction than the model that most cancer survivors currently experience (non-continuous consultantled care).

These results are further demonstrated by the probability of take-up estimates (also reported in Figure 2). Assuming respondents had a choice between standard care and an alternative that only varied by who was seen, the probability of choosing follow-up by a registrar/trainee doctor was 0.32 , GP 0.31 , and specialist nurse 0.32 . However, if continuity of care, one-to-one counselling and dietary advice were also offered, the probabilities of choosing a registrar/trainee, GP or specialist nurse-led service (compared with consultant-led one) increased to $0.88,0.84$ and 0.89 , respectively that is, the majority of respondents would choose non-consultant-led care.

Differences in preferences between survivors of different types of cancer are shown in Table 4. Differences between calculated utility levels of different models of follow-up for survivors of different cancers are shown in Figure 3. Melanoma and colorectal cancer patients had similar preferences; replacing consultants with alternative healthcare providers for these patients lead to comparable or slightly lower utility levels than standard care, as long as there was continuity of care. In these circumstances, registrars were the preferred healthcare providers for melanoma patients, while colorectal patients preferred to see a specialist nurse. If dietary advice and one-to-one counselling is included, both melanoma and colorectal cancer patients had a higher level of utility for seeing a specialist nurse, than for traditional consultant-led and non-continuous follow-up. Breast cancer patients had a strong preference not to see a GP, which cannot be compensated for by continuity of care. On the other hand, care provided by a registrar or a specialist nurse with continuity of 
Table 4. Results of regression analysis (random effects logit) for respondents with different cancers

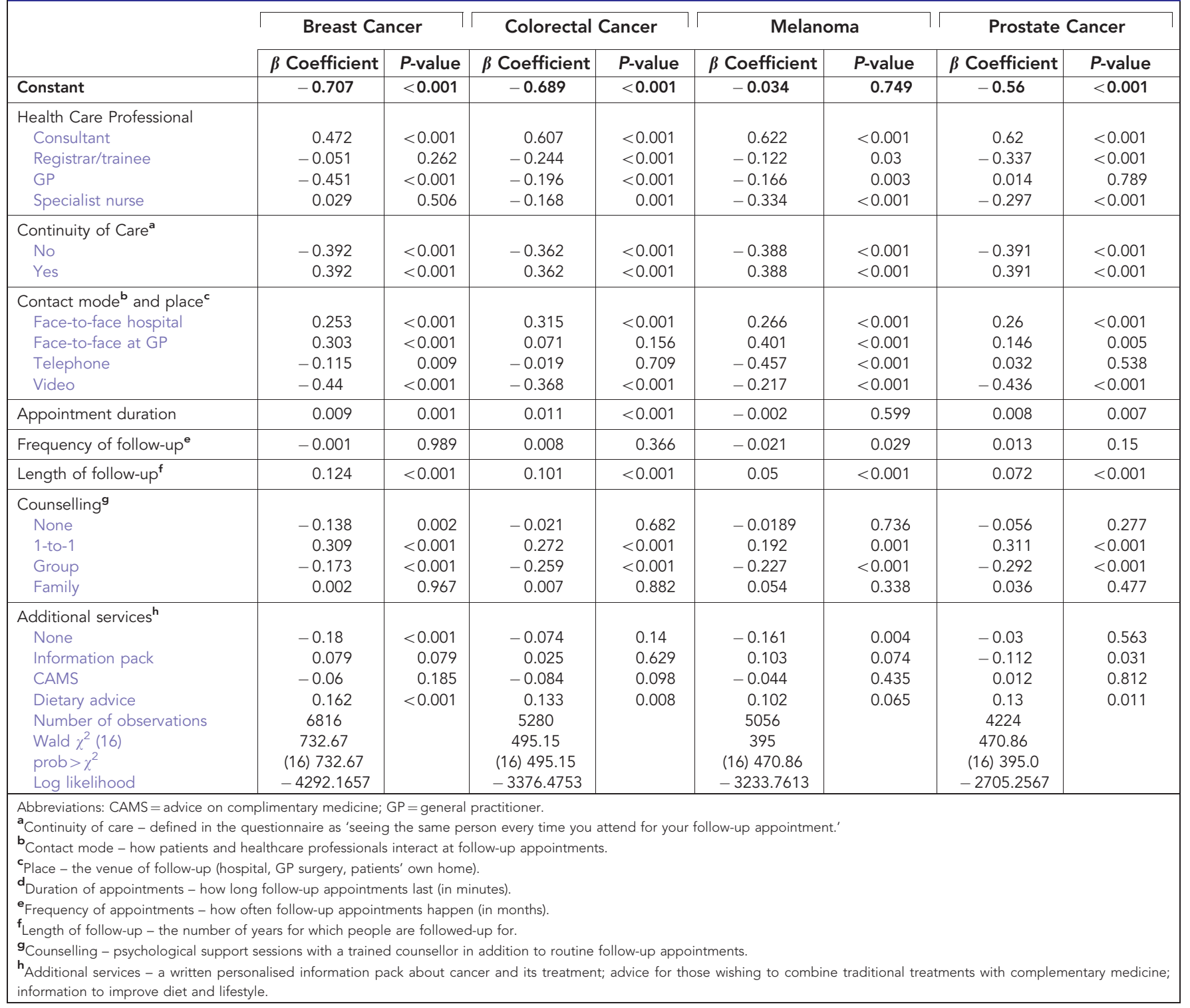

care resulted in higher utility values than consultant-led care without continuity. Breast cancer patients valued significantly one-to-one counselling and dietary advice; when offered these services in addition to continuity, these patients appeared willing to trade-off seeing a consultant for any other healthcare professional. Prostate cancer patients had higher utility from seeing a GP with continuity of care than a consultant with no continuity. However, with respect to seeing a registrar or specialist nurse, these patients would be compensated for not seeing a consultant only by receiving continuity of care, and oneto-one counselling and dietary advice.

Subgroup analysis was conducted, looking at how preferences differed across age, gender, time since diagnosis, having experienced a cancer recurrence and travelling time to attend follow-up appointments. No consistent patterns were observed.

\section{DISCUSSION}

Summary of main results. Respondents overall preferred continuous, face-to-face consultant-led follow-up. There were some important differences in the preferences expressed by survivors of melanoma, breast, prostate and colorectal cancer. Importantly, respondents appeared willing to receive follow-up by a specialist nurse, trainee specialist doctor or GP, provided that they were compensated by other changes in their follow-up, notably greater continuity of care. This finding suggests scope to seek more costeffective ways of delivering cancer follow-up care.

Strengths and limitations. This was the first DCE exploring the follow-up preferences of survivors of four different cancers, including three (melanoma, colorectal and prostate cancer) that have never been studied previously. We recruited a large number of cancer survivors. Content validity of the DCE was obtained by grounding the attributes and levels in the literature, information from interviews with people surviving the four cancers and discussions with specialists currently delivering structured followup to cancer survivors. The questionnaire was carefully revised during piloting. Internal validity was assured by including checkrecheck consistency tests, and excluding respondents who failed them. The usable response rate of $56.6 \%$ was high compared with other DCEs (Kimman et al, 2010; Bessen et al, 2014). 


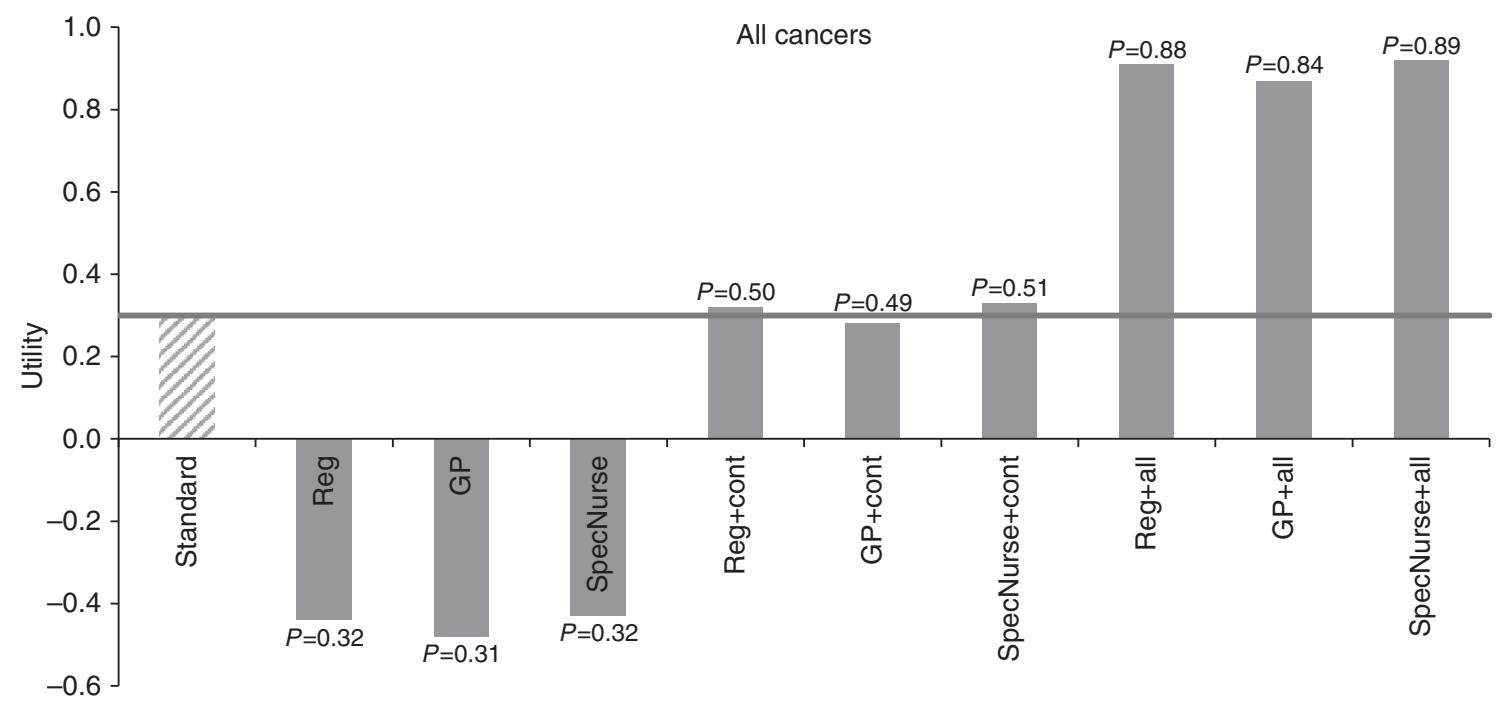

Figure 2. Graph displaying utilities expressed for alternative models of care by cancer survivors overall. Reg = registrar doctor; GP = general practitioner; SpecNurse = specialist nurse; cont = continuity of care; all = continuity of care; dietary advice and one-to-one counselling; $P=$ probability of uptake estimate.
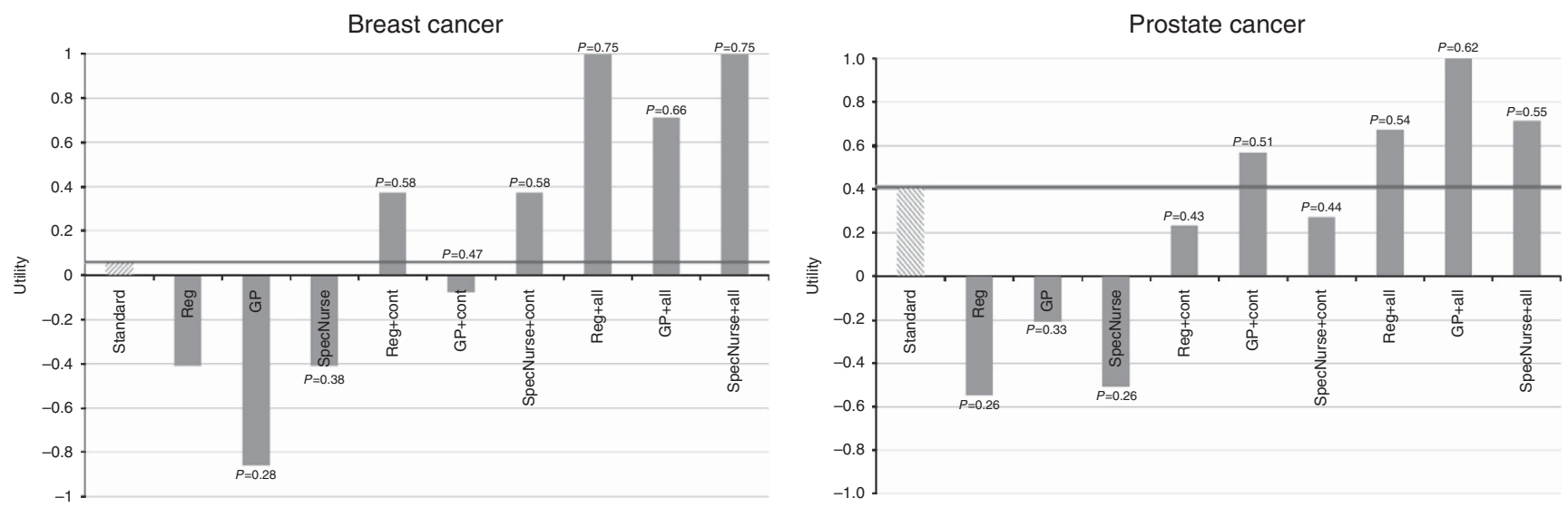

Colorectal cancer
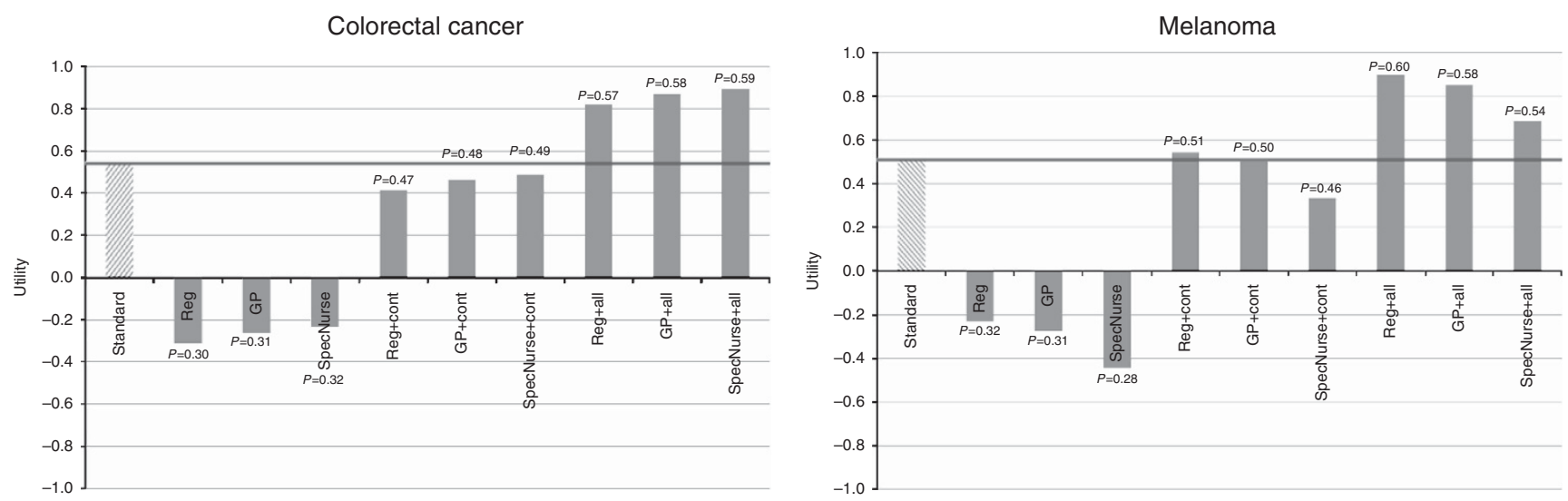

Figure 3. Graphs displaying utilities expressed for alternative models of care by survivors from different cancers. Reg=registrar doctor; $\mathrm{GP}=$ general practitioner; SpecNurse = specialist nurse; cont = continuity of care; all= continuity of care; dietary advice and one-to-one counselling; $P=$ probability of uptake estimate.

Some limitations should be noted. DCEs explore patients' stated preferences; without checking external validity, we cannot be sure that people would make the same choices in real life situations. Furthermore, people's preferences for cancer follow-up are complex. Our DCE included those attributes, which our exploratory work suggested were most important to patients. However, we acknowledge that there may be other important factors that were not identified from the literature search or interviews and which we have not included, such as amount of time taken of work, travelling time to home and the ability of a particular provided to manage other medical issues simultaneously. Additionally, some of the levels within attributes reflected those that patients told us during the interviews they would ideally like rather than what is offered, or possible, within the NHS. It also worth reflecting that 
patients may prefer elements of health service provision, which are not supported by the evidence. The study was conducted in Northeast Scotland; our results may not be generalisable if people surviving cancer elsewhere have different preferences. It is possible that the views of non-respondents, those providing invalid responses or patients not currently receiving follow-up, differ from those of participants included in this paper. Preferences of patients not currently under follow-up may be especially important since current arrangements may not be meeting their needs; future research should attempt to access these views. Furthermore, our results may have been affected by status quo bias (endowment effect), whereby respondents may prefer services or goods that they have experience of (Salkeld et al, 2000; Dorsey, 2010); a problem that may have been exacerbated by our respondents having most experience of specialist-led follow-up. We did collect the data on the different providers that respondents had seen for their follow-up care (Table 2) but did not ask them to specify the usual provider. More accurate data on the provider currently delivering our respondents' current follow-up could have enabled us to account more effectively for status quo bias and we recommend that future researchers should consider doing so (Ryan and Ubach, 2003).

Context with other literature. We are aware of only two previous studies, from The Netherlands and Australia, exploring preferences for structured follow-up of women treated for breast cancer (Kimman et al, 2010; Bessen et al, 2014). For the first time, we have explored the preferences among people who have experienced one of the four cancers, enabling us to see if preferences vary between survivors of different cancers. We found some differences, which should discourage a 'one-size-fits-all' approach to redesigning cancer follow-up. The two previous studies found that respondents preferred to see the same specialist face-to-face. Our findings, of a strong preference for consultant follow-up, was consistent. It is worth noting that a strong preference for hospital-based and specialist-led care is perhaps slightly at odds with evidence that the model appears to be suboptimal (Aaronson et al, 2014). Furthermore, the Dutch study demonstrated that breast cancer survivors would be willing to trade-off seeing a specialist for follow-up from a specialist nurse in return for more frequent follow-up appointments (Kimman et al, 2010). Our study also found evidence that survivors of different cancers might accept follow-up form an alternative healthcare provider (specialist nurse, registrar or GP, depending on the type of cancer), provided that they receive continuity of care.

Cost considerations suggest that the development of a cadre of dedicated cancer follow-up nurses may offer the most economical option for the future. The current data (Curtis and Burns, 2015) shows that, in the UK a clinical nurse specialist has an hourly unit cost of $£ 59$ compared with $£ 60$ for a registrar, $£ 118$ for a GP and $£ 138$ for a surgical consultant. Furthermore, there is evidence that specialist nurses in extended roles can improve healthcare delivery and contain costs (Tsiachristas et al, 2015). Given current constraints in primary care in the UK, there are likely to be challenges in accommodating (even if acceptable to patients) the additional workload associated with transferring follow-up from secondary to primary care. In addition, there may be minimal cost gains compared with current consultant-led care. On the other hand, follow-up care delivered by registrars or trainees doctors could be cost-effective and preferred by some patients. New models involving doctors in specialist medical training would need to allow for these doctors moving between placements, especially since continuity of care appeared to be so important to participants.

However, beyond simple cost considerations, dedicated cancer follow-up nurses may also offer the best way forward in terms of quality. Specialist nurses are viewed by many cancer specialists as capable of delivering effective cancer follow-up care (Greenfield et al, 2009). Further, the unmet needs of survivors from different cancers are becoming increasingly understood (Burg et al, 2015). The growing literature reveals a complex set of practical, physical, psychological and emotional needs (Molassiotis et al, 2014; Hubbard et al, 2015; Russell et al, 2015; Watson et al, 2015). Follow-up delivered by a dedicated specialist nurse with whom a cancer survivor can build a personal and continuous relationship over several years offers great promise to address complex individual needs, which could conceivably include some of the components valued by our respondents, such as counselling and dietary advice (The Health Foundation, 2014). However, further research is needed to provide evidence of the best models and additional components of effective cancer follow-up.

\section{CONCLUSION}

This study has shown that overall survivors of different cancers living in Britain prefer to receive follow-up from consultants. We also found that cancer survivors may be willing to trade-off between existing and novel attributes of follow-up care, and that the follow-up preferences appear to vary between survivors of different cancers. Our data are important as the nature of cancer survivorship evolves and as traditional cancer follow-up becomes increasingly difficult to sustain (National Cancer Survivorship Initiative, 2014). An emerging specialist nurse workforce may represent the ideal opportunity to determine and implement novel and cost-effective models of cancer follow-up care built around the preferences of individual cancer survivors.

\section{ACKNOWLEDGEMENTS}

We acknowledge the time taken by our participants in the study. We also thank: Amanda Cardy of the Scottish Primary Care Research Network who assisted MPM in administering the questionnaire mailings; Mrs Hazel Riley, CAPC, University of Aberdeen, who assisted MPM with the data entry; Drs Graham Macdonald, Marianne Nicolson, Leslie Samuel and Radha Todd, cancer specialists working at Aberdeen Royal Infirmary, who supported us by generating lists of their clinic attendees and screening the lists of potential recipients; Dr Verity Watson, HERU, University of Aberdeen who provided advice and support to MPM in the conduct of the analysis. Ethical approval: The North of Scotland Research Ethics Committee granted full approval for the qualitative interviews on 27 January 2011 $(11 / \mathrm{S} 0802 / 5)$ and the administration of the discrete choice experiment questionnaire on 17 May 2012 (12/NS/0051). Research support: MPM conducted this study during her $\mathrm{PhD}$ fellowship, which was funded by the Mearns Trust. An additional grant from the Friends of Anchor Charity funded the administration of the study questionnaire (GP057 RGB4085). Ethical and regulatory approval: Ethical approval for the semistructured interviews conducted to inform the study questionnaire was granted by the North of Scotland Research Ethics Committee (NosRES) on 27 January 2011 (11/S0802/5). Ethical approval for the discrete choice experiment questionnaire study was granted by the North of Scotland Research Ethics Committee on 17 May 2012 (12/NS/0051). Management approval to conduct the discrete choice experiment questionnaire study was obtained from the NHS Grampian Research and Development office on 29 May 2012. The University of Aberdeen acted as the research sponsor for both studies.

\section{CONFLICT OF INTEREST}

The authors declare no conflict of interest. 


\section{AUTHOR CONTRIBUTIONS}

PM and PCH conceived the study with advice from TP and MR. MPM conducted the interviews, designed the study questionnaire and conducted the full DCE study with support from PM, TP, $\mathrm{PCH}$ and MR. MPM and PN analysed the data with support from MR and TP. PM and PN drafted the first manuscript, which all the authors subsequently commented on.

\section{REFERENCES}

Aaronson NK, Mattioli V, Minton O, Weis J, Johansen J, Dalton SO, Verdonck-de Leeuw IM, Stein KD, Alfano CM, Mehnert A, de Boer A, van de Poll-Franse LV (2014) Beyond treatment: Psychological and behavioural issues in cancer survivorship research and practice. Eur $J$ Cancer Suppl 12: 54-64.

Bessen T, Chen G, Street J, Eliott J, Karnon J, Keefe D, Ratcliffe J (2014) What sort of follow-up services would Australian breast cancer survivors prefer if we could no longer offer long-term specialist-based care? a discrete choice experiment. Br J Cancer 110: 859-867.

Brennan PF, Strombom I (1998) Improving healthcare by understanding patient preferences: the role of compute technology. J Am Med Inform Assoc 5: 257-262.

Burg MA, Adorno G, Lopez EDS, Loerzel V, Stein K, Wallace C, Sharma DKB (2015) Current unmet needs of cancer survivors: analysis of open-ended responses to the American Cancer Society Study of Cancer Survivors. Cancer 121: 623-630.

Cancer Australia (2015) Australian Government Cancer Australia Clinical Best Practice Guidelines http://guidelines.canceraustralia.gov.au/clinicalbest-practice (accessed 26 March 2015).

Curtis L, Burns A (2015) Unit costs of Health and Social Care 2015. Personal Social Services Research Unit, University of Kent: Canterbury, UK.

Davies N, Batehup L (2011) Towards a personalised approach to aftercare: a review of cancer follow-up in the UK. J Cancer Surviv 5: 142-151.

Dirksen CD, Utens CMA, Joore MA, van Barneveld TA, Boer B, Dreesens DHH, van Laarhoven H, Smit C, Stiggelbout AM, van der Weijden $T$ (2013) Integrating evidence on patient preferences in healthcare policy decisions: protocol of the patient-VIP study. Implement Sci 8: 64.

Dorsey D (2010) Preferences, welfare, and the status-quo bias. Australas J Philos 88: 535-554.

Frew G, Smith A, Zutshi B, Aggarwal A, Jones P, Kockelberg R, Richards M, Maher EJ (2010) Results of a qualitative survey to explore both perceptions of the purposes of follow-up and preferences for methods of follow-up delivery among service users, primary care practitioners and specialist clinicians after cancer treatment. Clin Oncol 22: 874-884.

Gerard K, Ryan M, Amaya-Amaya M (2008) Introduction. In: Ryan M, Gerard K, Amaya-Amaya M (eds.) Using Discrete Choice Experiments to Value Health and Health care. Springer: Dordrecht, The Netherlands, pp 1-10.

Greenfield DM, Absolom K, Eiser C, Walters SJ, Michel G, Hancock BW, Snowden JA, Coleman RE (2009) Follow-up care for cancer survivors: the views of clinicians. Br J Cancer 101: 568-574.

Grunfeld E, Fitzpatrick R, Mant D, Yudkin P, Adewuyi-Dalton R, Stewart J, Cole D, Vessey M (1999) Comparison of breast cancer patient satisfaction with follow-up in primary care versus specialist care: results from a randomized controlled trial. Br J Gen Pract 49: 705-710.

Grunfeld E, Julian JA, Pond G, Maunsell E, Coyle D, Folkes A, Joy AA, Provenclar L, Rayson D, Rheaume DE, Porter GA, Paszat LF, Pritchond KI, Robidoux A, Smith S, Sussman J, Dent S, Sister J, Wernikowski J, Levine MN (2011) Evaluating survivorship care plans: Results of a randomized, clinical trial of patients with breast cancer. J Clin Oncol 29: 4755-4762.

Hellbom M, Bergelt C, Bergenmar M, Gijsen B, Loge JH, Rautalathi M, Smaradottir A, Johanse C (2011) Cancer rehabilitation: a Nordic and European perspective. Acta Oncol 50: 179-186.
Hubbard G, Venning C, Walker A, Scanlon, Kyle RC (2015) Supportive care needs of women with breast cancer in rural Scotland. Support Care Cancer 23: $1523-1532$.

Kimman ML, Dellaert BGC, Boersma LJ (2010) Follow-up after treatment for breast cancer: one strategy fits all? an investigation of patient preferences using a discrete choice experiment. Acta Oncol 49: 328-337.

McFadden D (1986) 'The choice theory approach to market research'. Market Sci 5: 275-279.

McFarlane KL, Dixon L, Wakeman CJ, Robertson GM, Eglinton TW, Frizelle FA (2012) The process and outcomes of a nurse-led colorectal cancer follow-up clinic. Colorectal Dis 14: e245-e249.

Molassiotis A, Brunton L, Hodgetts J, Green AC, Beesley VL, Mulatero C, Newton-Bishp JA, Lorigan P (2014) Prevalence and correlates of unmet supportive care needs in patients with resected invasive cutaneous melanoma. Ann Oncol 25: 2052-2058.

Murchie P, Nicolson MC, Hannaford PC, Raja EA, Lee AJ, Campbell NC (2010) Patient satisfaction with GP-led melanoma follow-up: a randomised controlled trial. Br J Cancer 102: 1447-1455.

National Cancer Institute (2015) Follow-up care after cancer treatment http://www.cancer.gov/cancertopics/coping/survivorship/follow-up-care (accessed 19 August 2016).

National Cancer Survivorship Initiative (2014) http://www.ncsi.org.uk/ (accessed 19 August 2016).

National Institute for Health and Care Excellence (2015) NICE, London https://www.nice.org.uk/guidance (accessed 19 August 2016).

Russell L, Gough K, Drosdowsky A, Schofield P, Aranda S, Butow PN, Westwood JA, Krishnasamy M, Young JM, Phipps-Nelso K, King D, Jefford M (2015) Psychological distress, quality of life, symptoms and unmet needs of colorectal cancer survivors near the end of treatment. J Cancer Surviv 9: 462-470.

Ryan M, Ubach C (2003) Testing for an experience endowment effect within choice experiments. Appl Econ Lett 10: 407-410.

Ryan M, Watson W, Gerard K (2008) Practical issues in conducting a discrete choice experiment. In: Ryan M, Gerard K, Amaya-Amaya M (eds) Using Discrete Choice Experiments to Value Health and Healthcare. Springer: Dordrecht, The Netherlands, pp 73-97.

Salkeld G, Ryan M, Short L (2000) The veil of experience: do consumers prefer what they know best? Health Econ 9: 267-270.

Scottish Intercollegiate Guideline Network (2015) SIGN, Edinburgh http://www.sign.ac.uk (accessed 19 August 2016).

Sloane NJA (2013) A library of orthogonal arrays. Available at http://neilsloane.com/oadir/ (Accessed 23 February 2015).

The Health Foundation (2014) Patient-centred Care Made Simple: What Everyone Should Know About Patient-centred Care. The Health Foundation: London, UK.

Tsiachristas A, Wallenburg I, Bond CM, Elliot RF, Busse R, van Exel J, Rutten-van Molken MP, de Bont A (2015) Costs and effects of new professional roles: evidence from a literature review. Health Policy 119: $1176-1187$

Watson E, Shinkins B, Frith E, Neal D, Hamdy F, Walter F, Weller D, Wilkinson C, Faithful S, Wolstenholme J, Sooriakumaran P, Kastner C, Campbell C, Neal R, Butcher H, Matthews M, Perera R, Rose P (2015) Symptoms, unmet needs, psychological well-being and health status in survivors of prostate cancer: implication for redesigning follow-up. BJU Int 117: E10-E19.

Watson V, Becker F, de Bekker-Grob E (2016) Discrete choice experiment response rates: a meta-analysis. Health Econ; e-pub ahead of print 27 April 2016; doi:10.1002/hec.3354.

Wong SF, Norman R, Dunning TL, Ashley DM, Lorgelly PK (2014) A protocol for a discrete choice experiment understanding preference of patients with cancer towards their cancer care across and metropolitan and rural regions in Australia. BMJ Open 4: e006661.

This work is published under the standard license to publish agreement. After 12 months the work will become freely available and the license terms will switch to a Creative Commons AttributionNonCommercial-Share Alike 4.0 Unported License. 